International Journal of Engineering \& Technology, 7 (4) (2018) $1970-1976$
International Journal of Engineering \& Technology
SPC
Website: www.sciencepubco.com/index.php/IJET
doi: $10.14419 /$ ijet.v7it.15550
Research paper

\title{
An objective study of behavior of permanent magnet synchronous motor under abnormal conditions
}

\author{
Zaid H. Al-Tameemi ${ }^{1}$ *, Hayder H. Enawi ${ }^{2}$, Karrar M. Al-Anbary ${ }^{3}$, \\ Dalya H. Al-Mamoori ${ }^{1}$, Hussam M. Almukhtar ${ }^{4}$ \\ ${ }^{1}$ Technical College /Al-Mussaib, Al-Furat Al-Awsat Technical University, Iraq \\ ${ }^{2}$ Engineering College, Babylon University, Iraq \\ ${ }^{3}$ Biomedical department, Warith Al-Anbiyaa University,Iraq \\ ${ }^{4}$ Middle Refineries, Najaf Refinery, Ministry of Oil, Iraq \\ *Corresponding author E-mail: zaid_altameemi@tcm.edu.iq
}

\begin{abstract}
Permanent magnet synchronous motors (PMSM) can be used directly in place of the induction motors (I.M) for several industrial applications since it is characterized by high efficiency, high power factor, and high power compared to I.M. However, this type of motor suffers from some abnormal conditions that result in minimizing power quality such as voltage sags, temporary disturbances, and faults within the network. In this paper, the behavior of PMSM has been studied under the above conditions in a Matlab/Simulink environment. It was noticed that such problems caused an increase in the amount of torque and current in this motor which impacted negatively on the motor speed and influenced the behavior of PMSM.
\end{abstract}

Keywords: PMSM; Short Interruptions; Faults; Broken Rotor Bar.

\section{Introduction}

In the last few years, permanent magnet synchronous motors(PMSM) have gained a considerable attention in the industries and academic world [1]. Practically, PMSMs are considered more desirable than induction motors (IM) with respect to high duty factor industrial applications such as pump, fan, and compressor because of its high efficiency, subordinate life cycle, high power factor, and less sensitivity to supply frequency and voltage deviations [2,3]. It is worth mentioning that its use is increasing because of the decreasing cost of commercial magnets. The excitation of PMSM can be supplied partially by using the magnets that are placed in the rotor and could be obtained partly by using the line current. A squirrel cage is supplied to hasten PMSM from a standstill when begun 'across the line' [4]. During the last three decades, many researches have been implemented in order to test PMSM for eco-technique feasibility and stability in both transient and steady states. Conversely, the researches carried out on the reliability of PMSM in the reallife scenarios (subjection to high power quality challenges) are limited [5]. Currently, power quality is a major concern in the electrical power utility field because of modern equipment and other motors which are sensitive to changes in frequency and voltage. Voltage sags, harmonics, and short disturbances are the major problems related to power quality that impact on motor performance. It should be clear that more than $80 \%$ of the power quality- related issues are concerned with the occurrence of short interruptions [6]. The previous studies focused only on the analysis of I.M under abnormal conditions and ignored PMSM performance. Therefore, this paper will shed light on the behavior of PMSM under short-time disturbances and faults. A Matlab/Simulink environment was used to conduct this study.

\section{Short interruptions}

A short interruption can be defined as the whole loss of voltage whether on single phase or more for certain periods ranging from 0.5 to 3 cycles [6]. A momentary disturbance always has the same cause as long disturbances, such as an inappropriate protection intervention and a fault in clearing the protection. When a source is relinked automatically within 1 minute, the produced case is called a short disturbance ; however, a manual restoration of the supply leads to long interruptions. Automatic reconnections can be implemented by closing the circuit breaker that cleared the resulting fault [7]. These interruptions have a significant impact on PMSM which is designed to function in normal conditions such as a balanced sinusoidal, periodic, steady-state voltage which can cause huge current and torque transients.

\subsection{Occurrence of voltage interruption}

PMSM is designed to operate on sinusoidal, periodic, steady-state voltages. Short disturbances can increase the amount of torque and current in this motor. When PMSM is disconnected from the source, the current in the stator circuit halts and flow into the PMSM. This, in turn, contributes to the deceleration of the rotor. Once there is a supply disturbance, the PMSM is misplaced directly; then, the rotating magnetic field produced by the stator current disappears. On the other hand, the rotating magnetic field generated by the magnets is maintained on the decelerating rotor. 


\section{Effect of broken rotor bar on PMSM}

In the last two decades, many researchers studied some of the faults that occur in machines, including broken rotor bar faults. Since 1980, several studies have been carried out in the field of broken rotor detection. Douglas (2003)studied this type of fault in the rotor using FFT method and Discrete Wavelet Transformer in a transient state by changing the load [8]. A discrete pack transformer has been reportedly used to detect broken rotor bar faults [8].It is worth mentioning that rotor failures account for about $10 \%$ of total faults that occur in machines[9]. In this regard, many reasons can contribute to damaging rotor bars, such as thermal stress,mmanufacturing defects, magnetic and mechanical stresses.

\section{Impact of fault on PMSM}

This type of fault is deemed as a power-related electrical problem which leads to the loss of one or more phases that supply a motor [10]. This situation impacts negatively on the behavior of motors, as demonstrated in Case3.

\section{Impact of fault on PMSM within grid}

Power quality is considered as an essential branch of electric power engineering. It plays a significant role in delivering quality power for industrial use. Many problems can contribute to decreasing the power quality in a system, such as voltage sag caused by some faults during specific periods, thereby, costing several millions of dollars [11]. Therefore, this section sheds light on some system problems in the presence of PMSM during faults.

\section{Simulation results}

To understand the impact of the aforementioned faults, different cases have been considered. The motor data are given as shown in each case.

Case1: short interruption

A PMSM with specific parameters given in Table 1 is simulated in a Matlab/Simpower system.

Table 1: Motor Parameters

\begin{tabular}{llll}
\hline \multicolumn{4}{c}{ Table 1: Motor Parameters } \\
\hline Voltage in volt & 220 & Flux linkage & 0.1852 \\
\hline Frequency in $\mathrm{Hz}$ & 50 & No. poles & 8 \\
Stator resistance $(\mathrm{ohm})$ & 1.6 & & \\
Armature inductance $(\mathrm{H})$ & 0.000395 & & \\
\hline
\end{tabular}

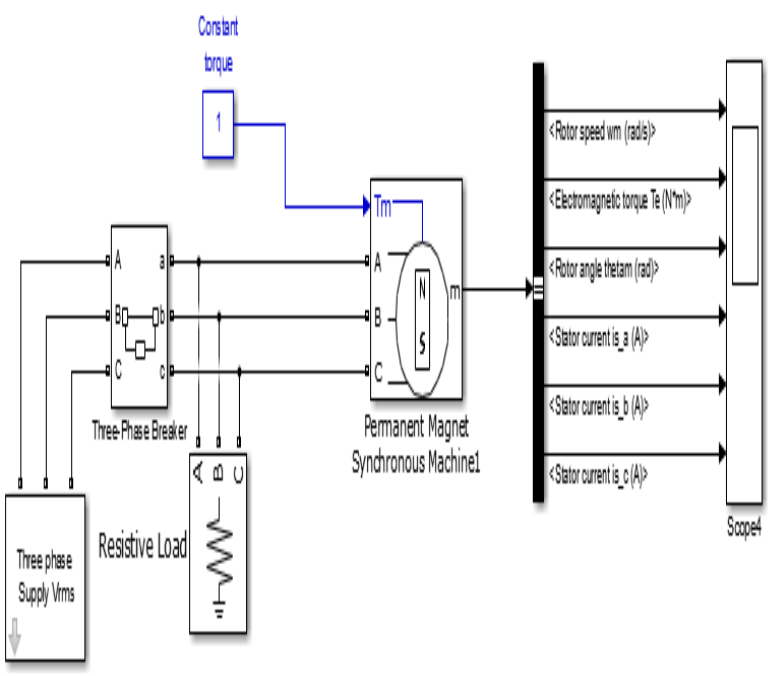

Fig. 1: PMSM Under Short Interruptions.

A three-phase supply is disconnected at 0.2 seconds once the PMSM reached a steady state. The behavior of PMSM is evaluat- ed under different cycle interruptions ( 2 - 6 cycles) as shown in the figures below. The speed is observed to greatly reduce because of the 2,4,6, and 8 interruption cycles carried out in the supply. A synchronism of the motor is achieved after 0.04 to 0.16 seconds which is less than the starting time of the motor .Figures2, 3, and 4 showed the stator currents falling to zero after all the interruptions.

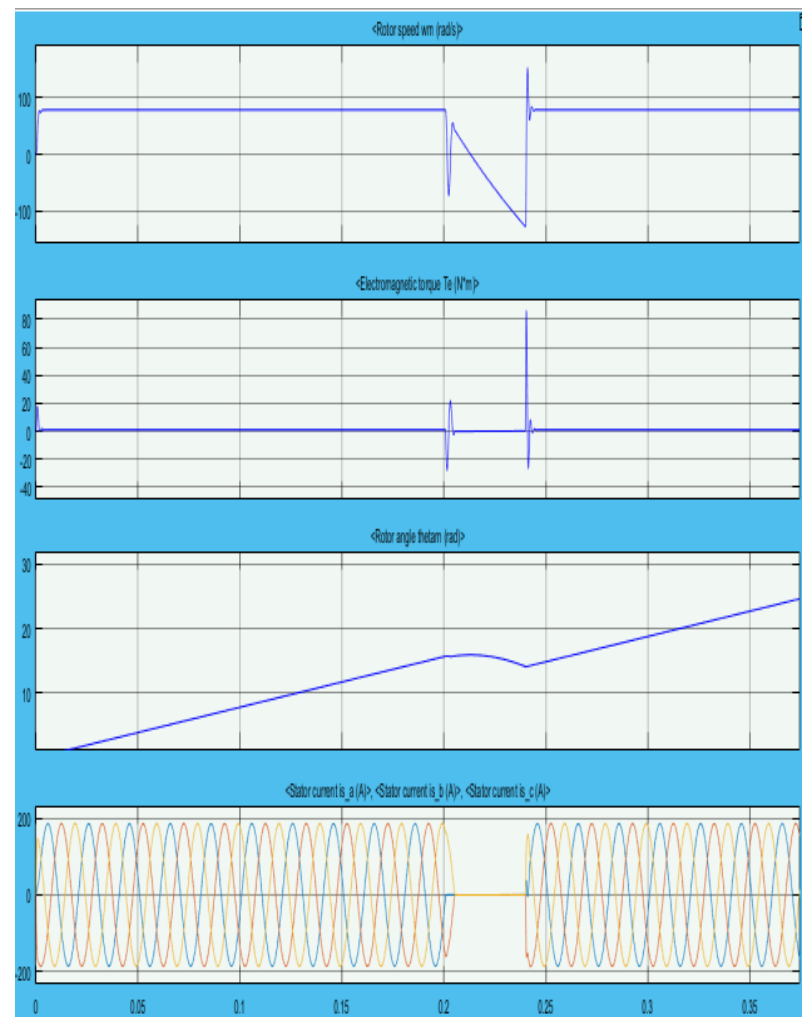

Fig. 2: Speed, Torque and Stator Current at 2 Cycle Interruption.

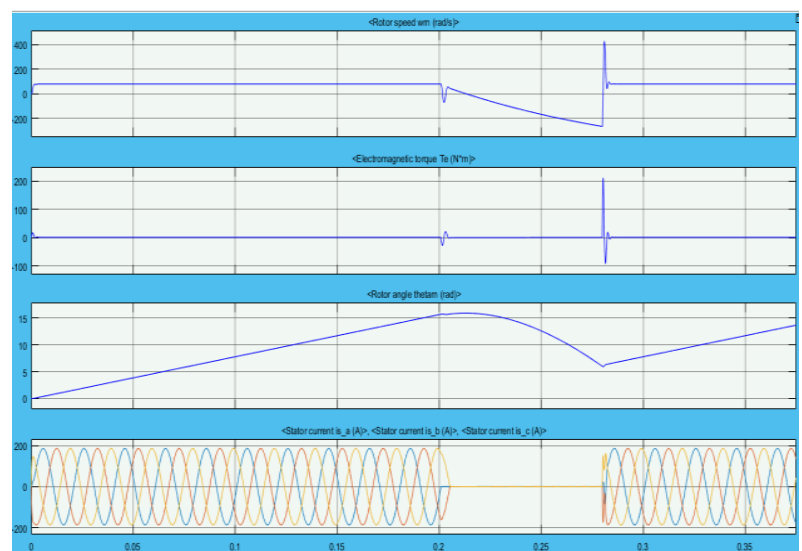

Fig. 3: Speed, Torque and Stator Current at 4 Cycle Interruption.

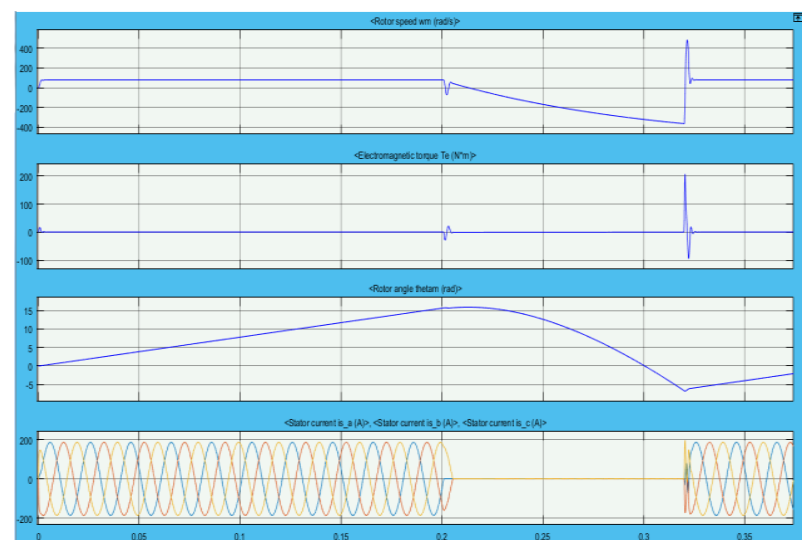

Fig. 4: Speed, Torque and Stator Current at 6 Cycle Interruption. Case2: Broken Rotor Fault 
The dynamics of a sudden torque change on the PMSM is considered. The PMSM is connected to three-phase sources with a small resistive load integrated into the network. This motor is initiated with a load of 1 p.u. When the motor has reached a steady state condition, the torque was suddenly increased from 1 to 20 at 1 second. This increment led to an accelerated torque and a decreasing motor speed as shown in Figure 7.

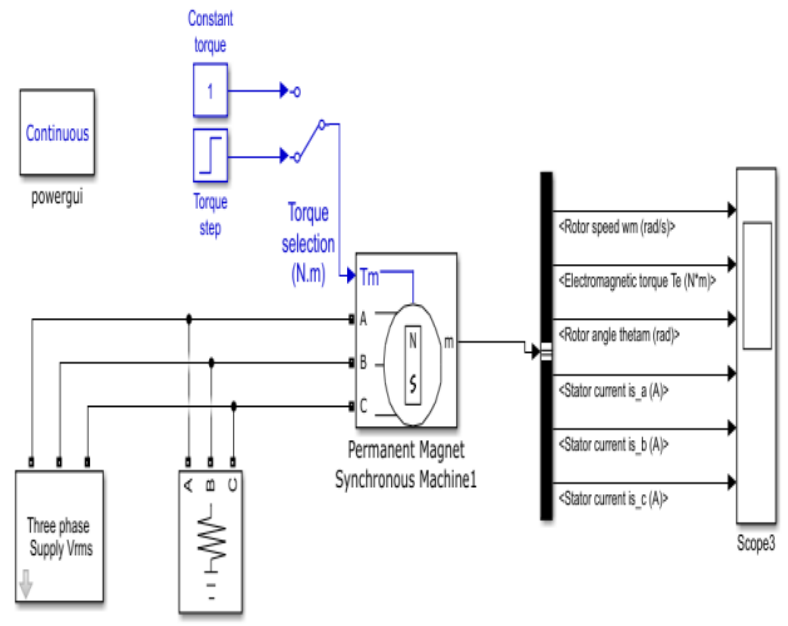

Fig. 5: PMSM Under Sudden Change in Torque.

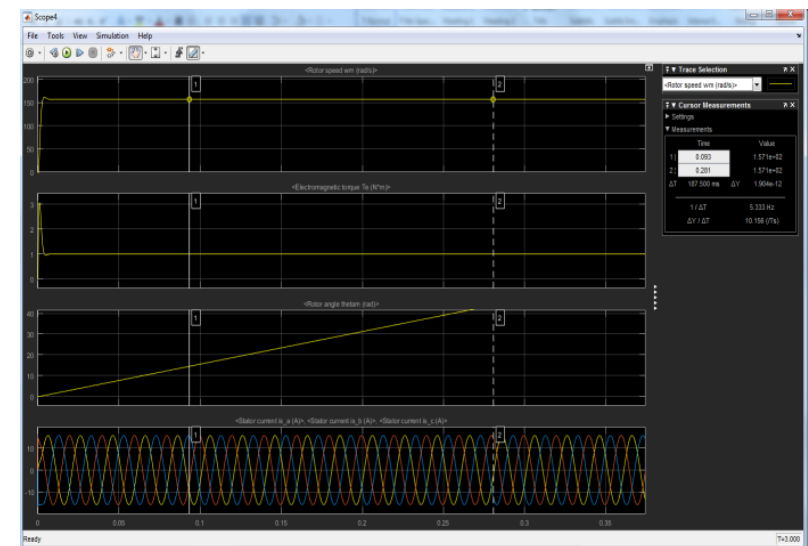

Fig. 6: PMSM Under Normal Torque

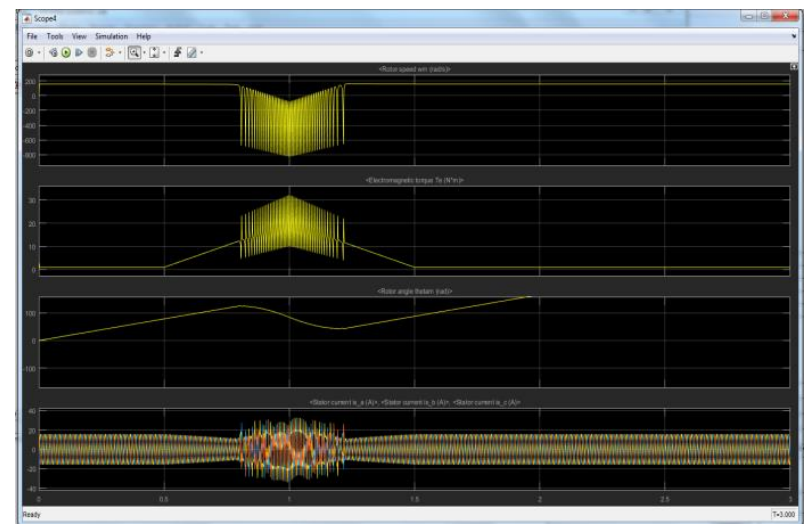

Fig. 7: PMSM Under Sudden Change in Torque.

Case3: Impact of fault on PMSM

PMSM model are created in a Matlab environment as shown in Figure 8. This mode is utilised to comprehend the impact of a three phase fault on the performance of PMSM, including torque and speed. The Simulink model comprises of 100 (peak) and $50 \mathrm{~Hz}$ 3 -phase source and three levels inverter. Two scopes are placed in the system to monitor the torque and speed under different load conditions in the presence of a three-phase fault. The fault is applied during 0.01 to $0.1 \mathrm{~s}$.

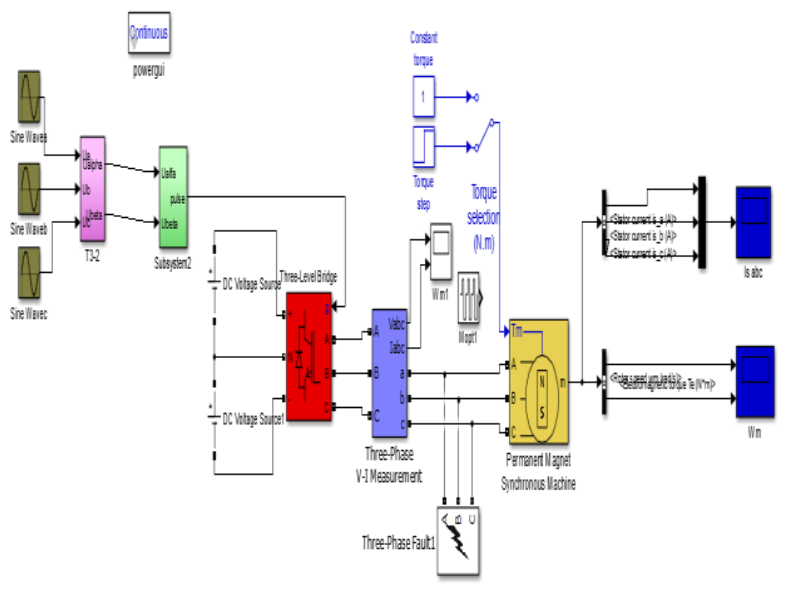

Fig. 8: PMSM Under Fault Condition.

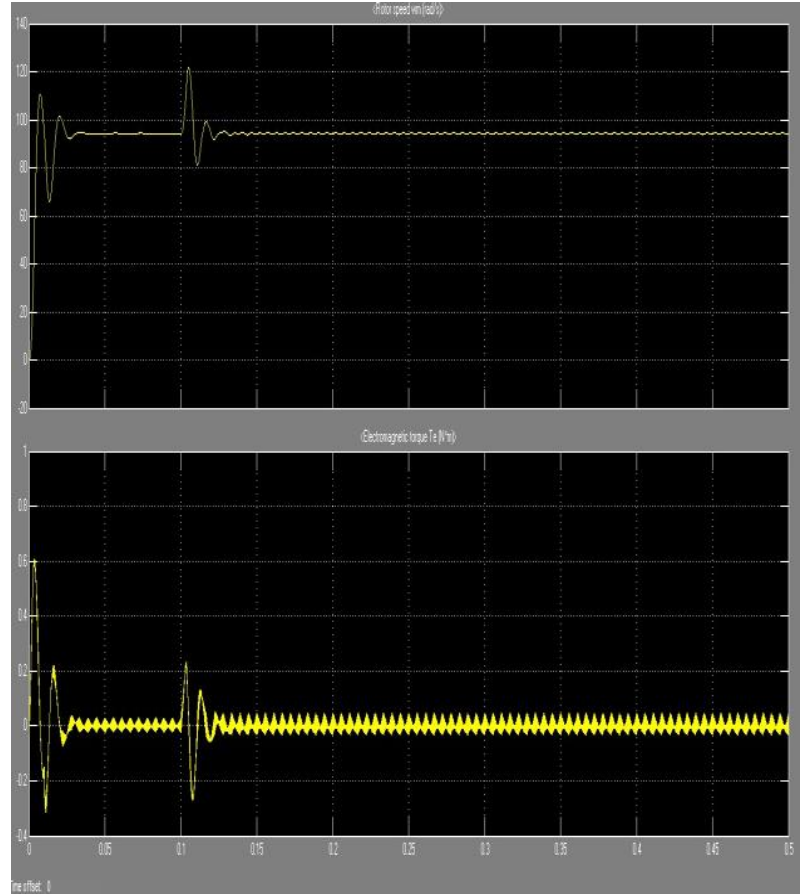

Fig. 9: Torque and Speed Under No.Load Condition.

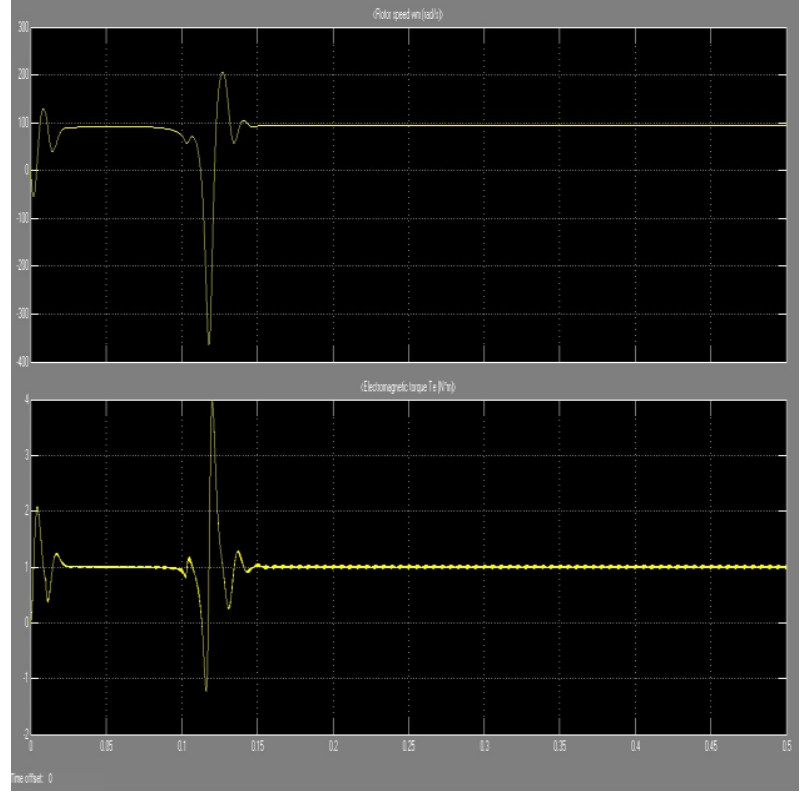

Fig. 10: Torque and Speed Under Constant Load Condition. 


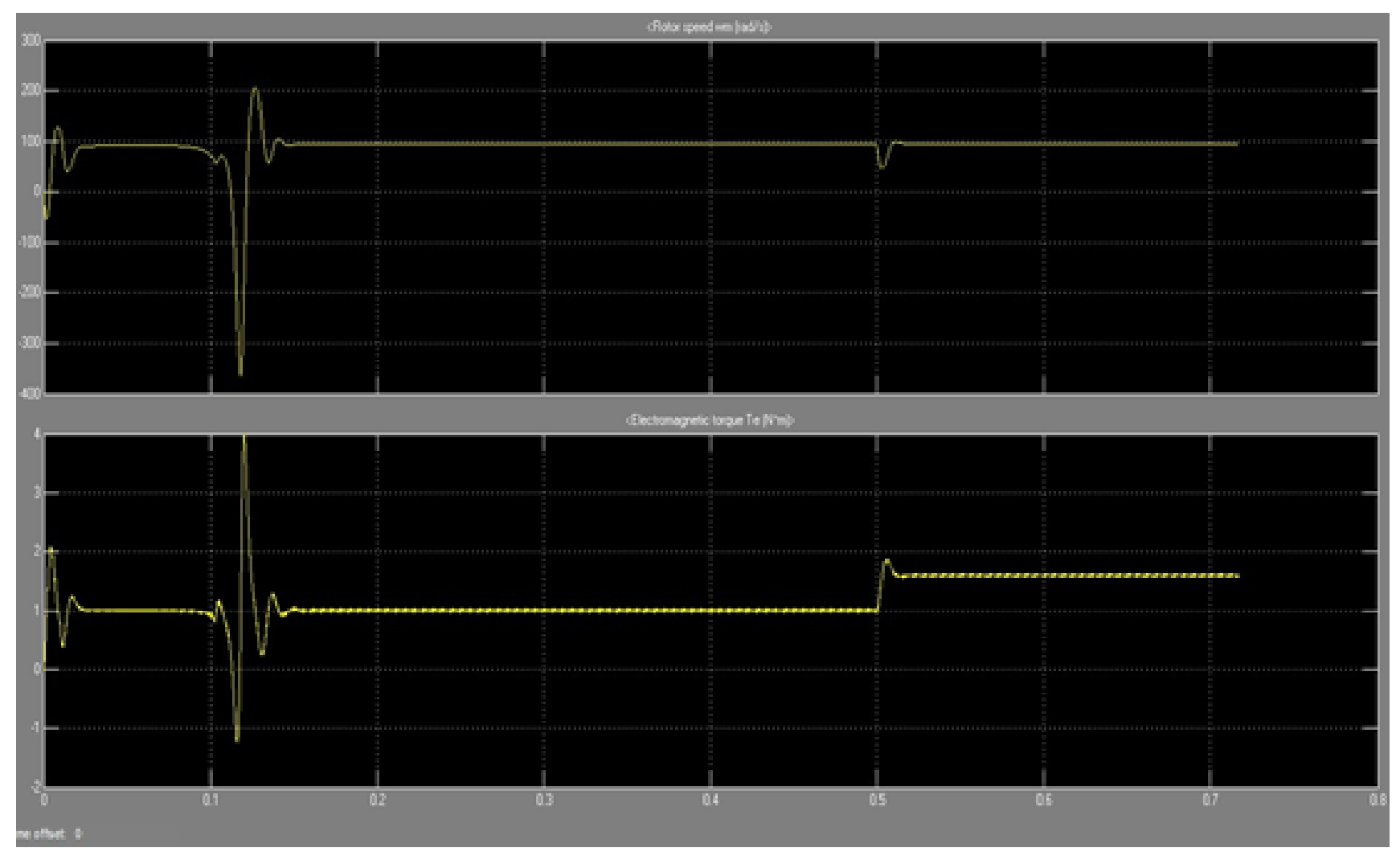

Fig. 11: Torque and Speed Under Variable Load Condition.

Case4: Impact Of Fault On PMSM Within Grid

Different scenarios are performed to understand the influence of faults on PMSMs that run within power networks, as demonstrated below.

\section{a) Normal condition}

The PMSM used here consists of $30 \mathrm{MVA}, 11 \mathrm{KV}$, and a $50 \mathrm{~Hz}$ 3-phase source. The feeder has a transformer of 11/0.4 KV, 1MVA delta/star. Two scopes were situated at 0.4 and $11 \mathrm{KV}$ bus to monitor the voltage waveforms and other waveforms including the rotor speed, rotor theta, and stator current under various situations. In this case, the model runs under a normal case

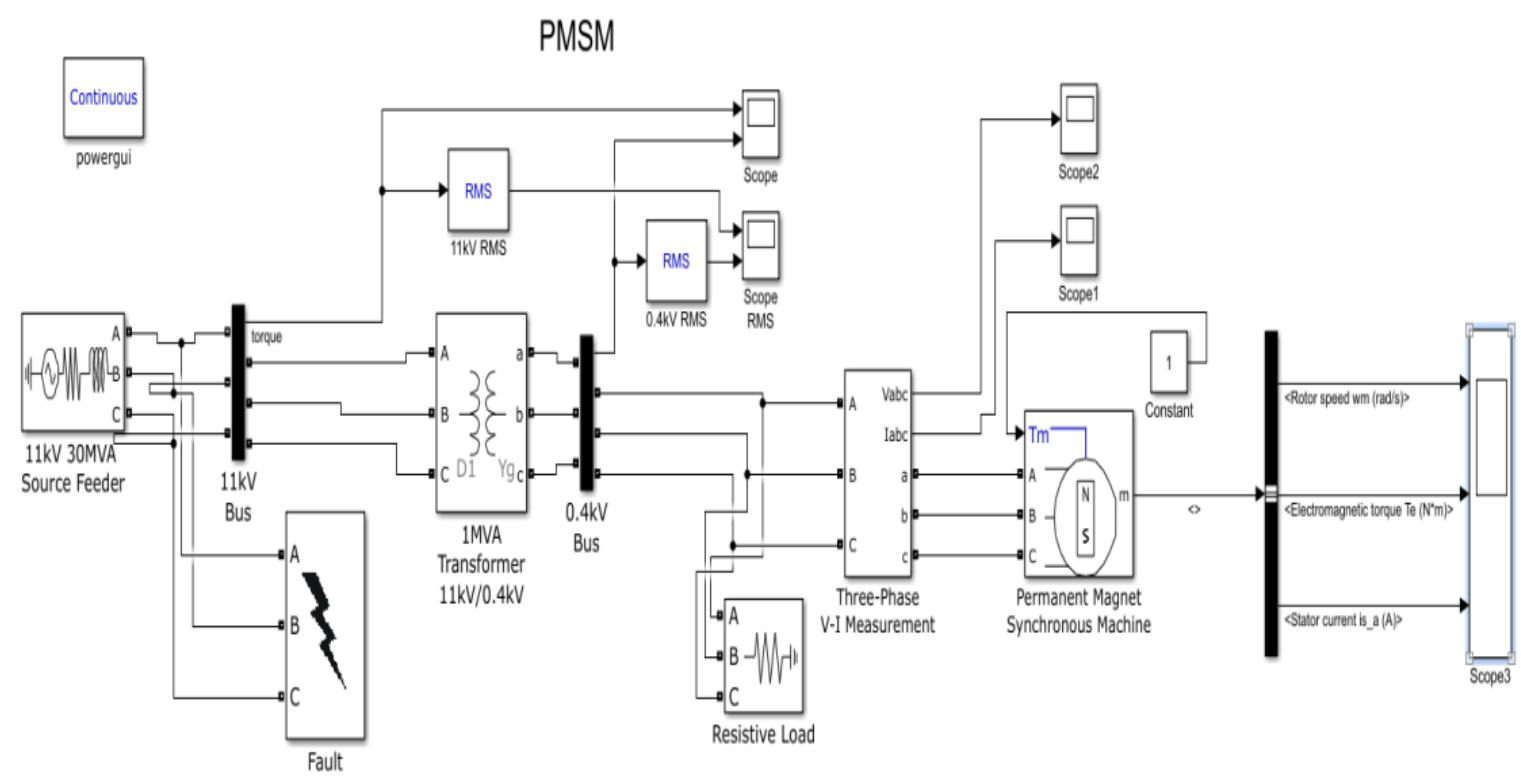

Fig. 12: PMSM under Fault within Grid. 


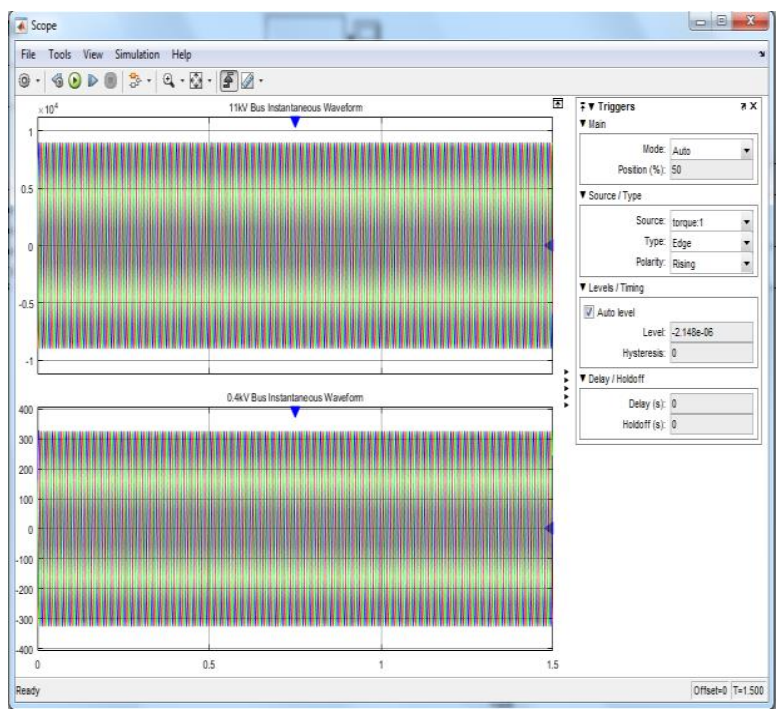

Fig. 13: PMSM under Normal Condition within Grid

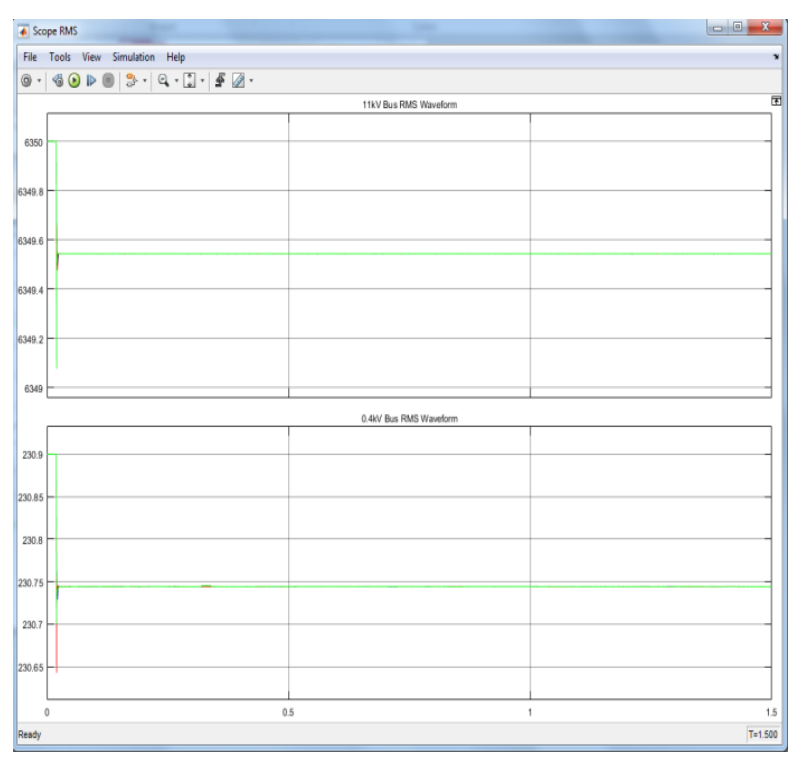

Fig. 14: Voltage Sag at RMS Scope.

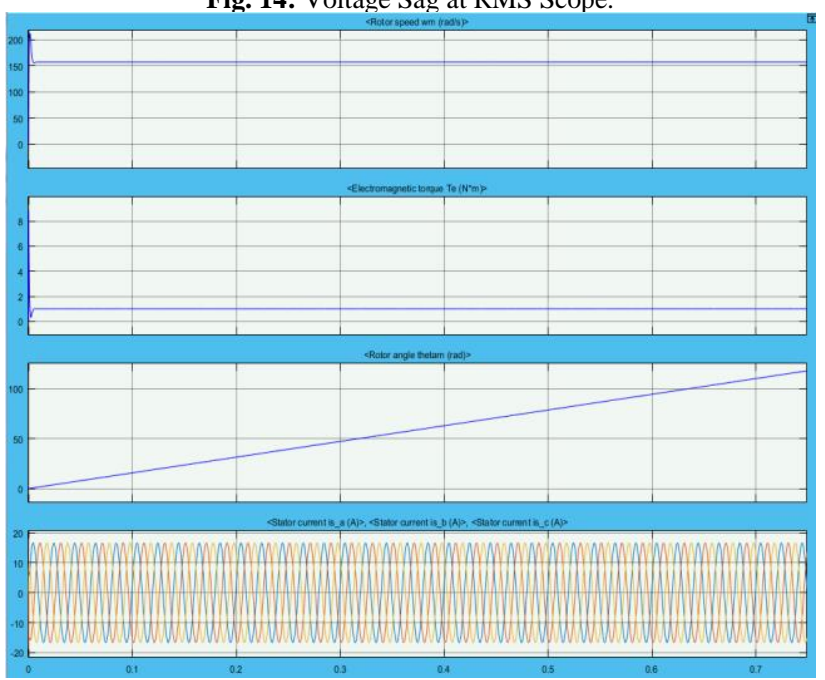

Fig. 15: Speed and Torque under Normal Condition.

b) Three phase fault

A line fault mode is created in a Matlab environment as shown in Figure 12. This mode is used to simulate a voltage sag due to line faults. The Simulink model comprised of a $30 \mathrm{MVA}, 11 \mathrm{KV}, 50$ $\mathrm{Hz}$ 3-phase source block feeding through 11/0.4 KV, 1MVA del- ta/star transformer with $10 \mathrm{~kW}$ resistive load in the line between the motor and a $0.4 \mathrm{KV}$ bus. Two scopes were placed at 0.4 and $11 \mathrm{KV}$ buses to monitor the voltage waveforms and other waveforms, including rotor speed, rotor theta, and stator current in the presence of a three-phase fault. The fault block was placed at 11 KV bus to simulate a three-phase fault. In this part, the performance of PMSM was investigated by applying a three-phase fault as shown in the figures below. Figures 17 and 18 show voltage sag waveforms resulting from a three-phase fault at $11 \mathrm{KV}$ feeder during the period of $0.15-0.25 \mathrm{~s}$. It is noted that the $11 \mathrm{kV}$ bus faces big voltage sags at all phases because of the low fault resistance between the three faulted lines as shown in the figures below:
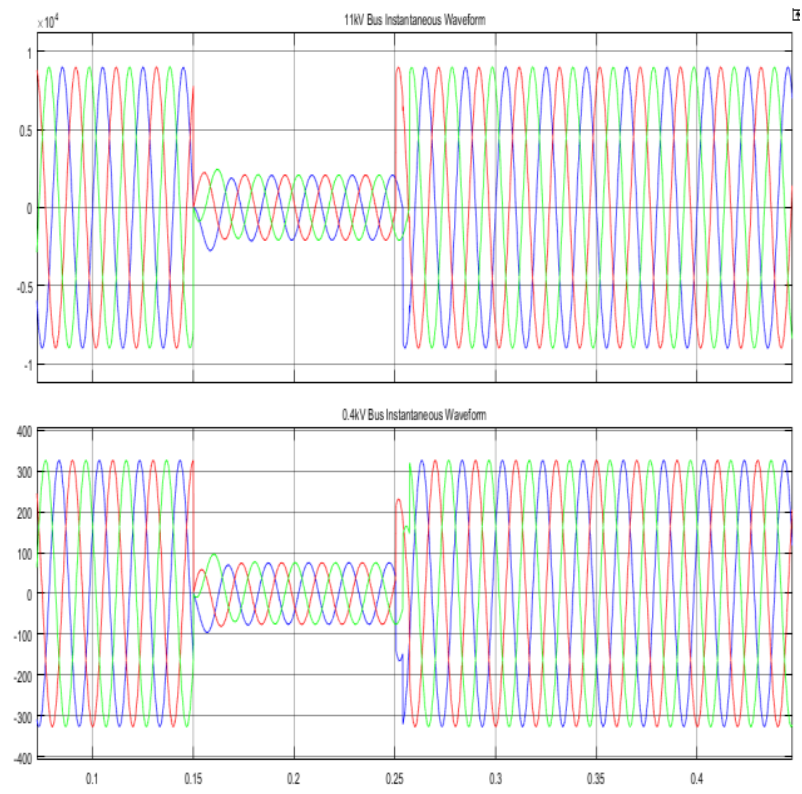

Fig. 16: Voltage Sag Caused by Three Phase Fault at 11 Bus Line.
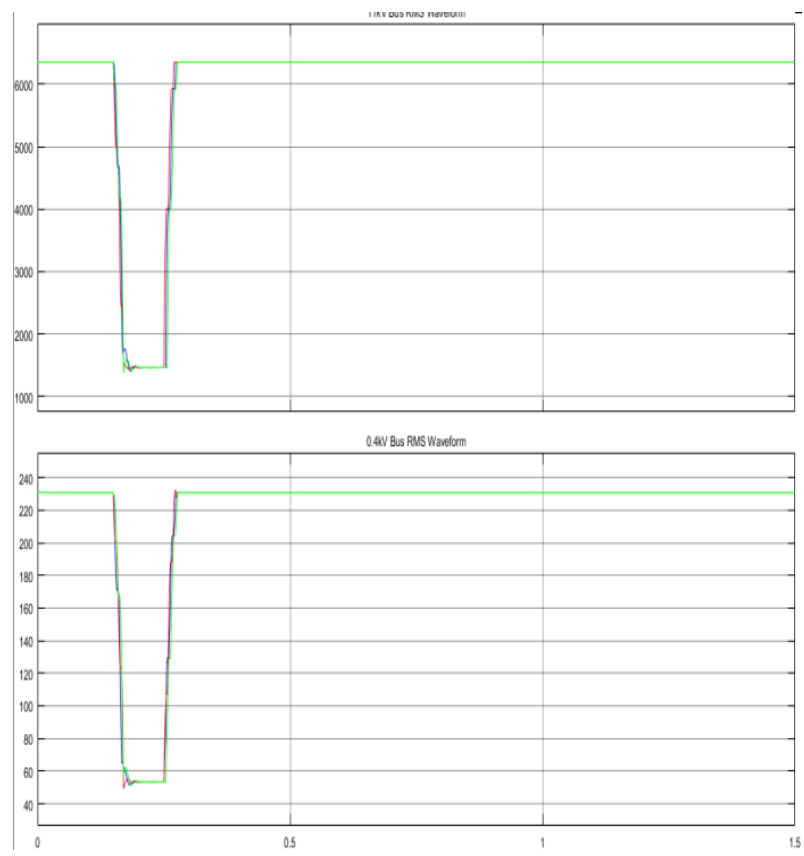

Fig. 17: Voltage Sag at RMS Scope.

It can be noted that voltage sag impacts negatively on the rotor speed, rotor angle theta, and stator current. Most of the values witnessed reductions and vibrations during this period while the stator current $-\mathrm{q}$ faces swelling as shown in the figure below. 


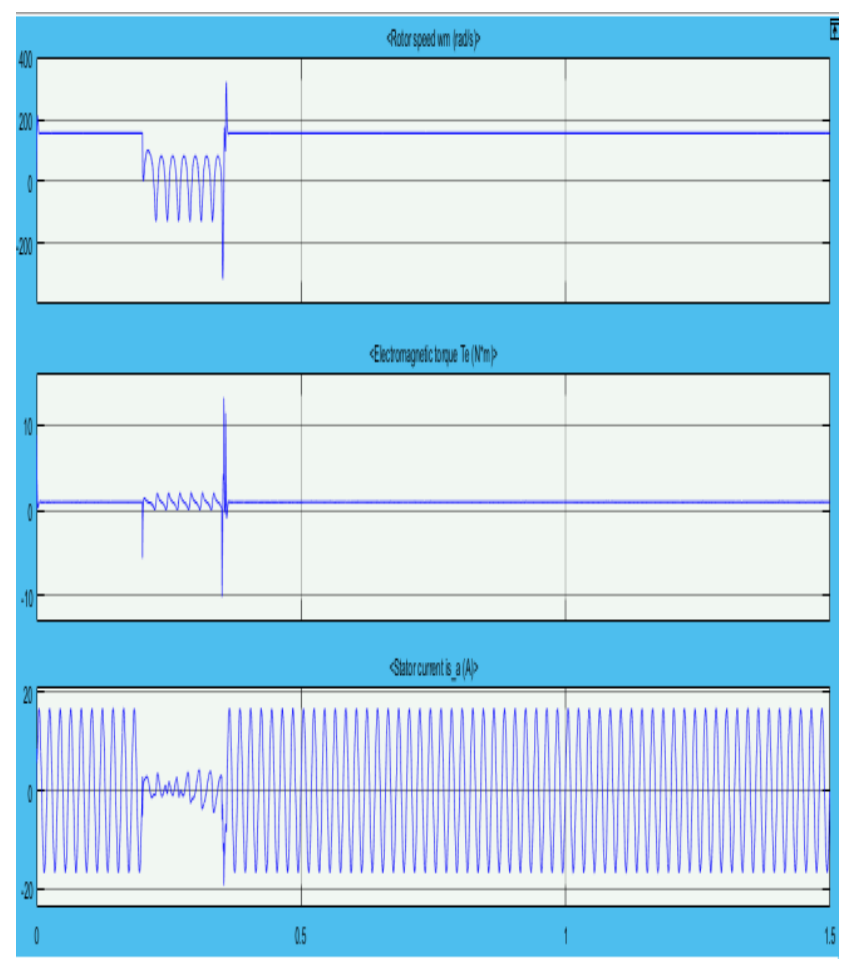

Fig. 18: Speed, and Torque under Three Phase Fault.

c) Line to line fault

In this section, the performance of PMSM is investigated by applying an L-L fault as shown in the figures below. Figures 19 and 20 show voltage sag waveforms caused by L-L faults that occurred at $11 \mathrm{kV}$ feeder during the period of $0.15-0.3 \mathrm{~s}$. It is noted that the 11 bus faces two voltage sags at different voltage magnitudes because of the high fault resistance $(8 \mathrm{ohms}$ ) between the two faulted lines as shown in figure 20 . The faulted phase at 0.4 $\mathrm{KV}$ bus faces a small voltage swell because there is no ground point in this type of fault, as well as the high fault resistance.

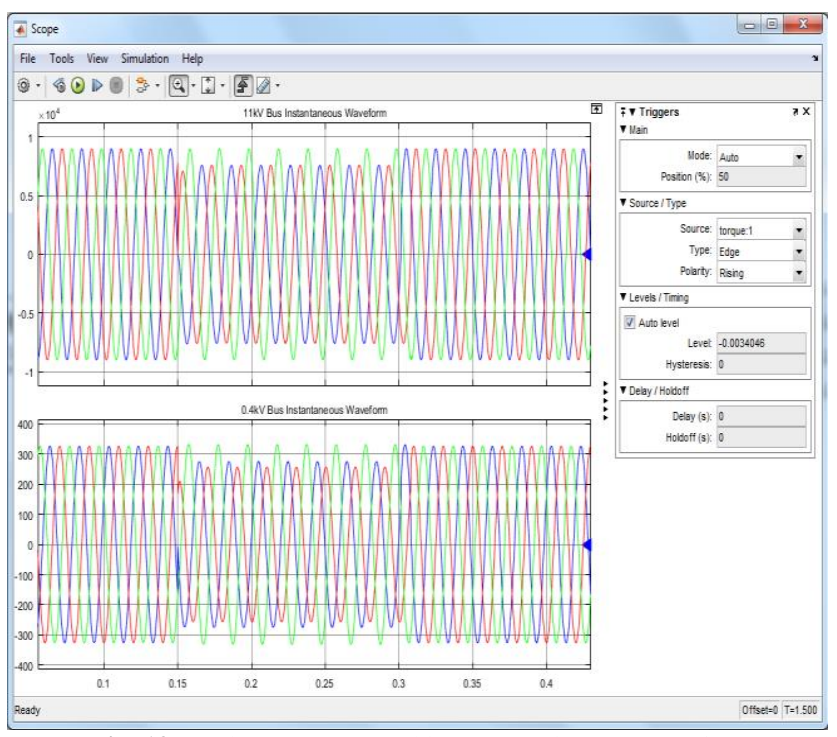

Fig. 19: Voltage Sag Caused by L-L Fault at 11 Bus Line.

In this study, voltage sag waveforms are presented in RMS scope. It represents the analysis of an L-L fault voltage sag waveform in the figure above. The voltage sag magnitudes for each phase are visualized. Small oscillations are observed to arise at the pre-sag and post-sag, as well as swells because of a phase shift during the fault [12].

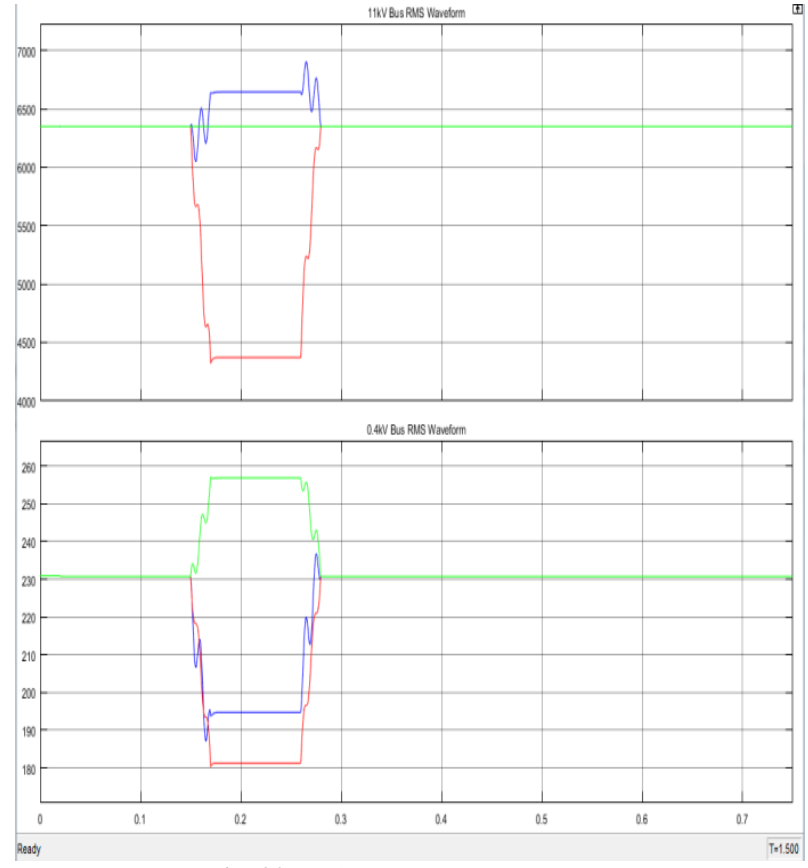

Fig. 20: Voltage Sag at RMS Scope.

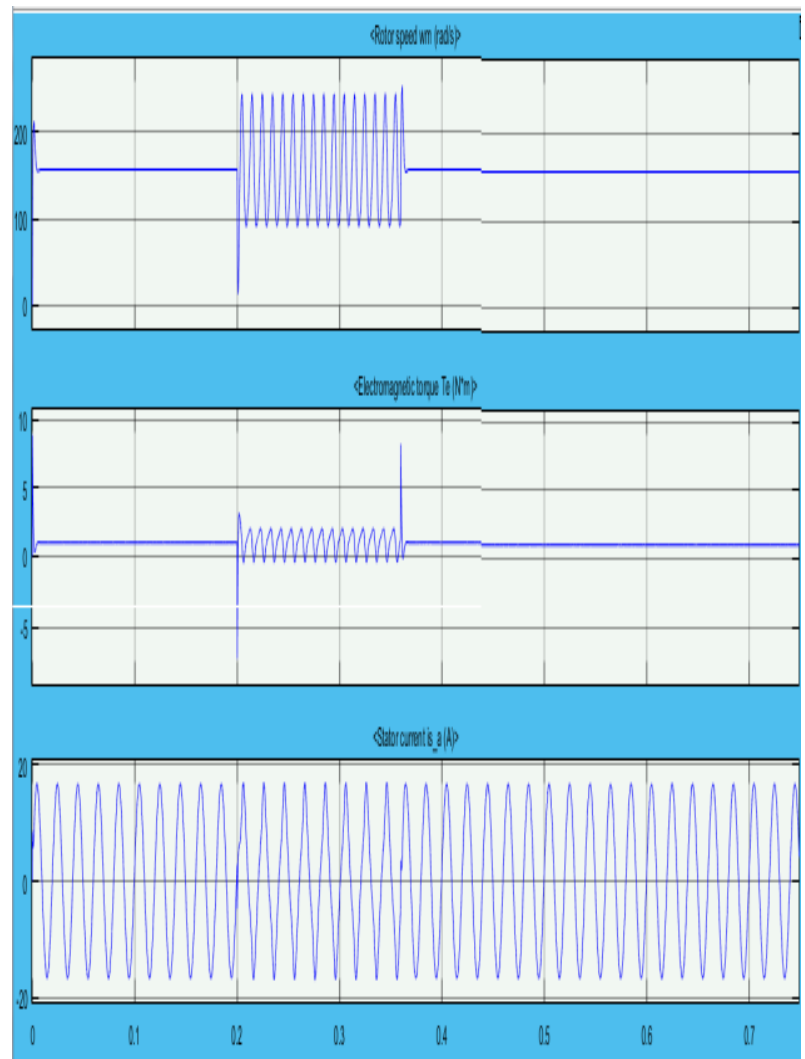

Fig. 21: Speed and Torque under L-L Fault Line to Ground Fault.

d) Line to ground fault

In this section, the performance of PMSM is investigated by applying an L-G fault as shown in the figures below. Figures 22 and 23 show voltage sag waveforms caused by an L-G fault at an $11 \mathrm{kV}$ feeder during the period of $0.15-0.3 \mathrm{~s}$. It was noted that the 11 bus faced small voltage sags at the faulted line because of the high fault resistance $(8 \mathrm{ohms})$ between the faulted line and the ground point. The phases at $0.4 \mathrm{KV}$ bus also faced a small voltage swell and sag because of the presence of a ground point and a high fault resistance in this type of fault [13]. 


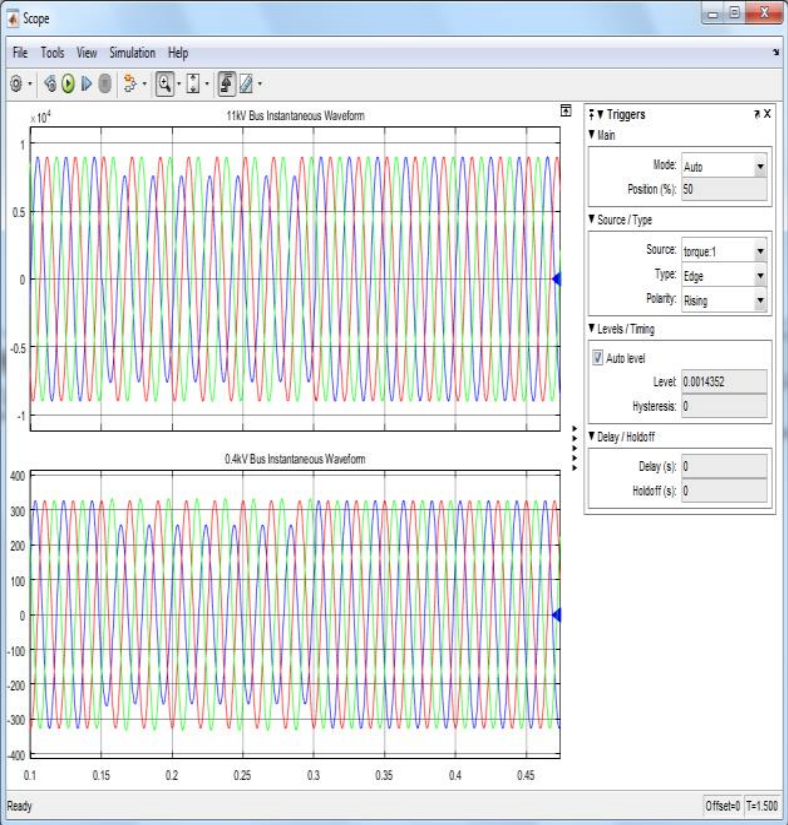

Fig. 22: Voltage Sag Caused by L-G Fault at $11 \mathrm{Kv}$ Bus Line.

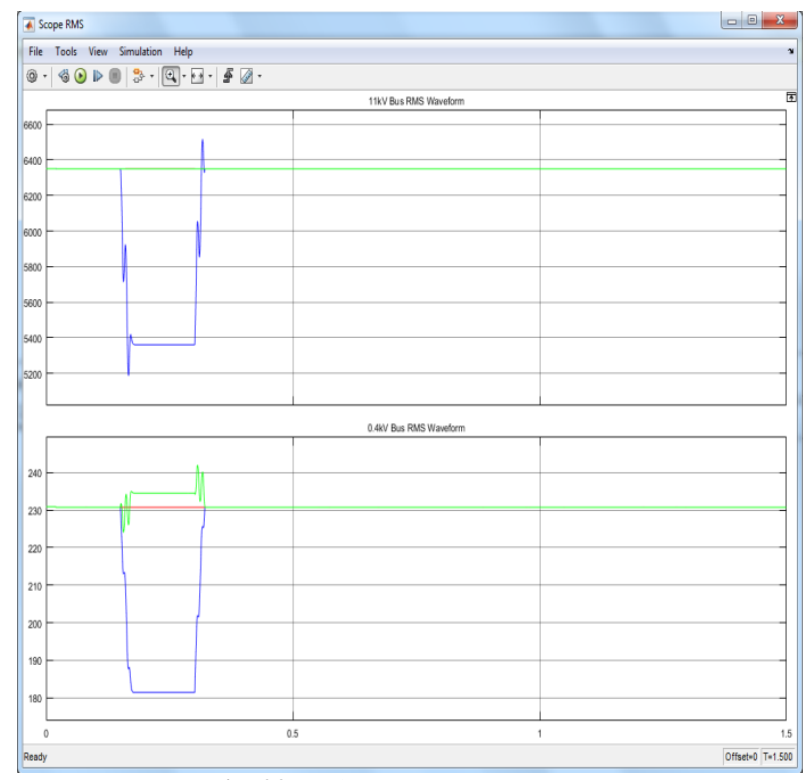

Fig. 23: Voltage Sag at RMS Scope.

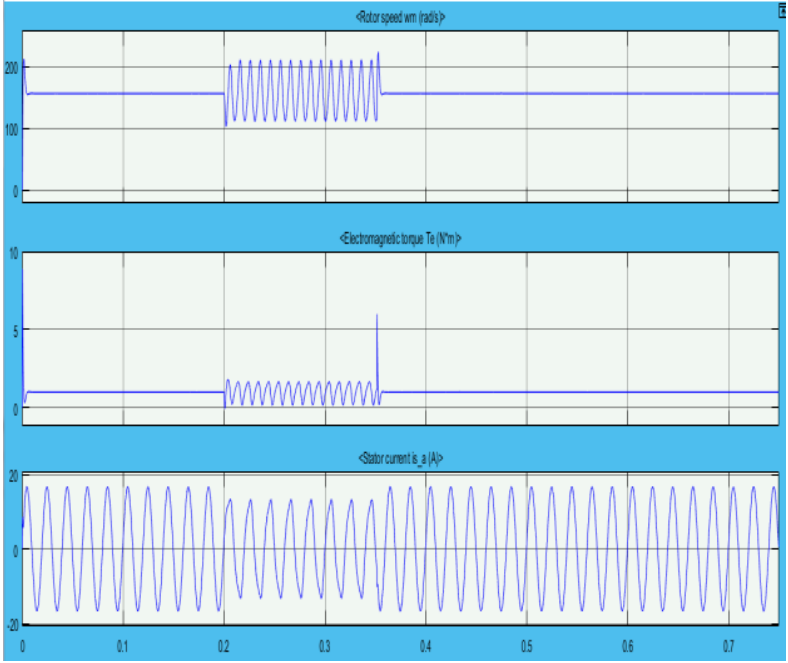

Fig. 24: Speed And Torque.

\section{Conclusion}

A PMSM is designed to work on the sinusoidal, periodic, steadystate voltage; hence, it is important to study the behavior of PMSM under different abnormal conditions such as short interruptions and sudden changes in the mechanical torque and faults. In these conditions, the torque, speed, and current are monitored to understand their impacts on the performance of PMSM. It is observed that short time interruptions contribute significantly to increasing the torque and currents which result in decreasing the motor speed. It is also noticed that resistance plays a vital role in reducing voltage sags during faults that occur in the power networks (including PMSM). The broken rotor bar is also found to play a negative role on the performance of PMSM, especially in accelerating the torque to an undesirable level.

\section{References}

[1] C.A. da Silva, J. Cardoso, and R. Carlson, "Analysis of a ThreePhase LSPMM by Numerical Method," IEEE Trans. Magnetics, Vol. 45, No. 3, March 2009, pp.1792-1795. https://doi.org/10.1109/TMAG.2009.2012823.

[2] Ugale, R.T., Bhanuji, A. and Chaudhari, B.N., 2009, January. A novel line start permanent magnet synchronous motor using twopart rotor. In TENCON 2009-2009 IEEE Region 10 Conference (pp. 1-5). IEEE. https://doi.org/10.1109/TENCON.2009.5395857.

[3] Ashok ,K. R., Balaji, K, Sensor less control of PMSM fed from three phase four switch inverter based on back EMF observer and sliding mode controller with fast reaching law. International Journal of Engineering \& Technology, vol. 7, no. 2, 2018, 725 - 731.https:// doi: 10.14419/ijet.v7i2.10847.

[4] Ugale, R.T., BalaKrishna, Y. and Chaudhari, B.N., 2008, April. Effects of short power interruptions and voltage sags on the performance of line start permanent magnet synchronous motor. In Power Electronics, Machines and Drives, 2008. PEMD 2008. 4th IET Conference on (pp. 184-188). IET.

[5] Miller, T.J.E., 1984. Synchronization of line-start permanentmagnet ac motors. IEEE Transactions on Power Apparatus and Systems,

(7), pp.1822-1828. https://doi.org/10.1109/TPAS.1984.318630

[6] Ugale, R.T. and Chaudhari, B.N., 2008, April. Effect of short power interruptions on performance of AC motors. In Industrial Technology, 2008. ICIT 2008. IEEE International Conference on (pp. 15). IEEE. https://doi.org/10.1109/ICIT.2008.4608323.

[7] Gomez, J.C., Morcos, M.M., Reineri, C. and Campetelli, G., 2001. Induction motor behavior under short interruptions and voltage sags. IEEE Power Engineering Review, 21(2), pp.11-15. https://doi.org/10.1109/39.896812.

[8] Douglas, H., Pillay, P. and Ziarani, A., 2003, June. Detection of broken rotor bars in induction motors using wavelet analysis. In IEEE International Electric Machines and Drives Conference, IEMDC'03. https://doi.org/10.1109/IEMDC.2003.1210345.

[9] An, G. and Li, H., 2017. Stator and Rotor Faults Diagnosis of Squirrel Cage Motor Based on Fundamental Component Extraction Method. International Journal of Rotating Machinery, 2017. https://doi.org/10.1155/2017/1576381.

[10] Karmakar, S., Chattopadhyay, S., Mitra, M. and Sengupta, S., 2016. Induction motor and faults. In Induction Motor Fault Diagnosis (pp. 7-28). Springer, Singapore. https://doi.org/10.1007/978981-10-0624-1_2.

[11] ollen, HJ, Society, IP, Society, IP \& Society, II 2000, Understanding power quality problems: voltage sags and interruptions, IEEE Press ; Wily-Interscience, New York : Hoboken, N.J.

[12] Mcgranaghan, M \& Roettger, B 2002, 'Economic Evaluation of Power Quality', Power Engineering Review, IEEE, vol. 22, no. 2, pp. 8-12. https://doi.org/10.1109/MPER.2002.981339.

[13] Djokic, S \& Milanovic, J 2006, 'Advanced voltage sag characterisation. Part 1: Phase shift', Iee Proceedings-Generation Transmission and Distribution, vol. 153, no. 4, pp. 423-430. https://doi.org/10.1049/ip-gtd:20050350. 